\title{
GAS CHROMATOGRAPHY-MASS SPECTROMETRY ANALYSIS AND ANTIOXIDANT ACTIVITY OF PUNICA GRANATUM L. PEELS AND ITS ROLE AS IMMUNOSTIMULANT AGAINST SCHISTOSOMA MANSONI INFECTION IN BIOMPHALARIA ALEXANDRINA
}

\author{
HANAN S MOSSALEM ${ }^{1}$, MOSAD A GHAREEB ${ }^{2 *}$, LAILA A REFAHY², ASMAA S MOHAMED ${ }^{2}$, MOHAMED R HABIB ${ }^{1}$ \\ ${ }^{1}$ Medical Malacology Laboratory, Theodor Bilharz Research Institute, Giza 12411, Egypt. ${ }^{2}$ Department of Medicinal Chemistry, Theodor
} Bilharz Research Institute, Giza 12411, Egypt. Email: m.ghareeb@tbri.gov.eg

Received: 08 September 2016, Revised and Accepted: 06 October 2016

\section{ABSTRACT}

Objective: To evaluate the antioxidant activity and chemical composition of Punica granatum L. and test it as immunostimulants against Schistosoma mansoni infection to Biomphalaria alexandrina snails.

Methods: Antioxidant activity was evaluated by measuring the free radical scavenging activity of the $90 \%$ defatted methanol extract (90\% DM) of $P$. granatum peels and its sub-derived fractions was evaluated via 2,2'-diphenyl-1-picrylhydrazyl and its chemical constituents were identified via gas chromatography-mass spectrometry (GC-MS) analysis. B. alexandrina snails were exposed to pomegranate extracts (PEs) for 1 month before their challenging with $S$. mansoni miracidia. Infection rates, immunological and histological parameters were, then, evaluated in PE-exposed snails and compared to controls.

Results: The antioxidants activities of PE, expressed as scavenging concentration at $50 \%$, were in the following order; $90 \%$ DM (12.45) $>n$-butanol (15.59) > ethyl acetate (21.36) > water (49.16) $\mu \mathrm{g} / \mathrm{ml}$, compared to $7.50 \mu \mathrm{g} / \mathrm{ml}$ for ascorbic acid. The infection rates of PE-exposed snails were $20 \%$, $50 \%, 60 \%, 70 \%$, and $80 \%$, respectively, for $90 \%$ DM, $n$-butanol, ethyl acetate, water, and dichloromethane extracts compared to $95 \%$ in control snails. The number of amoebocytes showed a significant increase, clear differentiation, and size increment in exposed snails compared to controls. Moreover, hermaphrodite glands histology shows a full maturity in the formation of reproductive cells in PE-exposed snails. The GC-MS analysis of the $90 \%$ DM extract revealed the presence of 36 compounds representing 93.1\% of the total composition. Piperidin-4-ol, 1,3-dimethyl-2,4,6-triphenyl (19.87\%), and 6,11-dihydroxy-5,12 naphthacenequinone-1-carboxylic acid (7.80\%) were the major components.

Conclusion: The identified compounds in 90\% DM extract of $P$. granatum may be responsible for the high antioxidant activity of the fruit and it may account for its immunostimulatory effect against $S$. mansoni infection in B. alexandrina.

Keywords: Punica granatum L., Antioxidant activity, Biomphalaria alexandrina, Schistosoma mansoni, Infection rate, Gas chromatography-mass spectrometry.

(C) 2017 The Authors. Published by Innovare Academic Sciences Pvt Ltd. This is an open access article under the CC BY license (http://creativecommons org/licenses/by/4. 0/) DOI: http://dx.doi.org/10.22159/ajpcr.2017.v10i1.15107

\section{INTRODUCTION}

Natural products from plants and herbs have been used extensively as alternative drugs for the treatment of a wide range of ailments and diseases $[1,2]$. Their use stem due to the undesired side effects and cost-prohibitive or limited effectiveness associated with the antibiotics, chemicals or drugs currently being used. Most of the well-known diseases are caused by oxidative stress occurring within the body as a result of chemical exposure or pathogen infection, whereby the affected organism cannot produce sufficient antioxidants to overcome the produced free radical, also known as reactive oxygen species $[3,4]$. Therefore, the body needs an exogenous source of antioxidants [5]. Plants or their byproducts are thus preferred because of their richness with phenolic, polyphenolic, alkaloid, quinone, terpenoid, lectin, and polypeptide compounds that proved to be effective alternatives to many synthetic compounds [6-8]. Natural plants have been used as immunostimulants to modulate the innate immune response and increase the body's resistance to infection and in prevention and treatment of various diseases $[9,10]$. Plant products such as phenolics and flavonoids play a major role in preventing or controlling infectious microbes [11]. Punica granatum L. (family Punicaceae) is usually recognized as pomegranate and is native to the Mediterranean area [12,13]. P. granatum has numerous applications in the traditional medicine worldwide for the treatment of many ailments and infectious diseases, i.e. helminthiasis, acidosis, dysentery, diarrhea, hemorrhage, acne, allergic dermatitis, and pile [14-16]. All parts of the pomegranate including fruits, bark, roots, and leaves reported to have antioxidant and therapeutic properties [17-19]. The most medically effective constituents of pomegranate are ellagitannins, punicic acid, anthocyanins, estrogenic flavonols, and flavones [20,21]. Many parasitic diseases depend on intermediate host organisms for the completeness of their life cycles. Controlling such diseases remains a great challenge, especially in developing countries. Most of the control initiatives are usually directed to the final host by administering drugs (chemotherapy) or application of chemical compounds to the intermediate host environments for eradication purposes. Either chemotherapy or chemical application toward intermediate hosts eradication is limited in approach and suffers many financial and logistical constraints [22]. An example of these diseases is schistosomiasis, which is considered a major public health problem in many tropical and sub-tropical countries with an estimated global burden of 240 million people infected [23] and close to 800 million at the risk of infection [24]. Schistosomiasis is caused by digenetic trematodes of the genus Schistosoma that depend on freshwater snails to complete their life cycle and infect human. Two main control strategies have been used to control schistosomiasis; (1) eliminating host snails using molluscicides, promoting good sanitation and health education [25-27] and (2) morbidity control by killing the worms in humans using chemotherapy approach $[27,28]$. However, schistosomiasis still prevalent due to the disadvantages 
related to the application of these control strategies such as the high financial cost of molluscicides application and drug administration, in addition to the emerging drug resistance in the laboratory $[29,30]$. In Egypt, schistosomiasis mansoni is still endemic in some parts of the country supported by the abundance of Biomphalaria alexandrina snails in the Egyptian freshwaters [31-34]. With regard to molluscicides, a number of perceived disadvantages of using niclosamide have been reported such as the necessity for repeated reapplication, difficulty to achieve uniform dispersal and area coverage, high costs due to repeated treatments, and collateral effects on amphibians and fish [26] The limitations of chemotherapy and mollusciciding prompted the need to new innovative control strategies. One possible mechanism is the effective interruption of the Schistosoma life cycle in snails to block the parasite's transmission, and thus truly preventing human schistosomiasis over the long-term $[26,35,36]$. This study aims to assess the effect of methanol solvent extracts of $P$. granatum on innate immunity and resistance of $B$. alexandrina to $S$. mansoni infection, as a control mechanism that can be used to block schistosomiasis transmission.

\section{METHODS}

\section{Plant materials}

The fresh fruits of $P$ granatum L. (family Punicaceae) were collected from markets in Giza, Egypt during 2015. The identification and authentication of the collected fruits was carried out by Prof. Dr. Wafaa Amer, Professor of Plant Taxonomy, Faculty of Science, Cairo University, Giza, Egypt.

\section{Extraction and fractionation}

The air-dried powdered peels of $P$. granatum $\mathrm{L}$. (1.5 kg) were soaked in $4 \mathrm{~L}$ of aqueous methanol (90\%) for 3 days at room temperature $\left(25 \pm 2^{\circ} \mathrm{C}\right)$. The crude methanolic extract was concentrated via rotatory evaporator to afford $220 \mathrm{~g}$, after that $210 \mathrm{~g}$ from evaporated methanol extract were defatted using $1.5 \mathrm{~L}$ petroleum ether $\left(60-80^{\circ} \mathrm{C}\right)$ to give petroleum ether extract (25 g) and 90\% defatted methanol extract (diabetes mellitus [DM]; $175 \mathrm{~g}$ ). The latter was suspended in distilled water, and extracted successively with dichloromethane (DCM) (1.5 L), ethyl acetate ( $2 \mathrm{~L}$ ), and $n$-butanol ( $2 \mathrm{~L}$ ), to obtain methylene chloride $(40 \mathrm{~g})$, ethyl acetate (15 g), $n$-butanol (50 g), and water (55 g) extracts. The obtained extracts were weighed and stored for further analyses.

\section{Free radical scavenging antioxidant activity}

The free radical scavenging antioxidant activity was determined according to Molyneux [37] and Ghareeb et al. [38]. Furthermore, the rapid screening of antioxidant by dot-blot and 2,2'-diphenyl-1picrylhydrazyl (DPPH) staining was carried out according to Shoeb et al. [39]. All solvents and reagents used were of analytical grade. DPPH and ascorbic acid were obtained from Sigma-Aldrich, UK. All other solvents used in the current research work were obtained from El-Nasr Pharmaceutical Chemicals Co./Egypt.

\section{Gas chromatography-mass spectrometry (GC-MS) analysis}

GC-MS analysis was performed using a GC (Agilent Technologies 7890A) interfaced with a mass-selective detector (MSD, Agilent 7000) equipped with a polar Agilent HP-5ms (5\%-phenyl methyl poly siloxane) capillary column ( $30 \mathrm{~m} \times 0.25 \mathrm{~mm}$ i. d. and $0.25 \mu \mathrm{m}$ film thickness). The carrier gas was helium with the linear velocity of $1 \mathrm{ml} /$ minute. The identification of components was based on a comparison of their mass spectra and retention time with those of the authentic compounds and by computer matching with the database of the National Institute of Standard and Technique (NIST08s), WILEY8, and Adams [40].

Effect of the pomegranate extracts (PEs) on $B$. alexandrina susceptibility to $S$. mansoni

\section{Biomphalaria collection and maintenance}

B. alexandrina snails were collected from the irrigation canals of Giza Governorate, Egypt, transferred and maintained at Medical Malacology Laboratory, Theodor Bilharz Research Institute, Egypt. The snail's colonies were kept in polyvinyl plastic trays $(8 \mathrm{~cm} \times 21 \mathrm{~cm} \times 31 \mathrm{~cm})$ containing dechlorinated tap water of about $6 \mathrm{~cm}$ in depth at room temperature $\left(25 \pm 1^{\circ} \mathrm{C}\right)$ for acclimation. The snails were supplemented with lettuce leaves daily and the blue green alga, Nostoc muscorum, was also added weekly as a dietary supplement. During the acclimation period, the snails were examined twice weekly for 6 successive weeks for any trematode infection. Only uninfected snails were used in the experiments (Shell diameter: 10-12 $\mathrm{mm}$ ).

\section{Exposure conditions and snails infection}

Five groups of uninfected Biomphalaria, each of 30 snails in triplicates (10 snails/replicate), were exposed to $200 \mathrm{ppm}$ (equivalent to the concentration at which the highest antioxidant activity was obtained) of each of PEs. Negative controls were also set up in triplicates using only dechlorinated water. The exposure of snails to the extracts was for 1 month and the solutions were changed every 3 days. PE-exposed and control snails were infected with miracidia hatched from $S$. mansoni ova obtained from Schistosome Biological Supply Center, Theodor Bilharz Research Institute. Exposure of snails to miracidia were done individually in $15 \mathrm{~mm} \times 17 \mathrm{~mm}$ glass vials with $1.0 \mathrm{ml}$ dechlorinated aerated tap water, under fluorescent light from 20 watt tubes, $30 \mathrm{~cm}$ far and temperature $24 \pm 1^{\circ} \mathrm{C}$. On the next day, the exposed snails were transferred to and maintained in standard aquaria previously described. Starting from the day 21-post miracidial exposure, the snails were examined individually and repeatedly for cercarial shedding in multi dishes under artificial light for 2 hrs (stimulant period) in $2 \mathrm{ml}$ of dechlorinated tape water/snail. All snails that died during the prepatent period were crushed between two slides and inspected under a microscope for immature parasite stages [41]. The snail's infection rate was calculated at the end of experiment by dividing number of shedding and positive crushed snails on the number of exposed snails [42].

\section{Hemocytes investigation}

Hemolymph samples were collected from each group of exposed snails by removing a small portion of the shell and inserting a capillary tube into the heart. The hemolymph pooled from 10 snails and collected in a $1.5 \mathrm{ml}$ Eppendorf tube according to Michelson [43] and kept in an icebox for microscopic examinations. Blood films were stained with leishman, giemsa stains and examined according to Mossalem et al. [35]. The number of each blood cell type was calculated and represented as a percentage per 100 of cells. Histological sections were also prepared from the hermaphrodite glands and examined under light microscope. Three snails from each group were crushed gently and the hermaphrodite gland was removed, fixed in Bouin's fluid for $5 \mathrm{~h}$ and then transferred to $70 \%$ alcohol. Further procedures were followed including dehydration in an ascending series of alcohol, clearing in xylol, and embedding paraffin. $5 \mu \mathrm{m}$ paraffin-embedded sections were stained with hematoxylin and eosin for general histological examination [44].

\section{Statistical analysis}

The antioxidant data were presented as mean \pm standard deviation of triplicates $(n=3)$ according to Annegowda et al. [45] using SPSS 13.0 program (SPSS Inc. USA). Comparisons among infection rates of snails and hemocytes percentages were performed using Chi-square test (pairwise vs. control). Limit for statistical significance was set at $p \leq 0.05$ (significance level of 95\%).

\section{RESULTS}

\section{DPPH free radical scavenging activity}

Analysis of the antioxidant activity of $P$. granatum extracts using free radical scavenging antioxidant activity assay with DPPH, revealed that the $90 \% \mathrm{DM}$ and $n$-butanol are the most potent antioxidants followed by ethyl acetate and water while no activity was recorded with petroleum ether and DCM extracts. The order of activities (expressed as scavenging concentration at $50 \%\left[\mathrm{SC}_{50}\right]$ values in $\mu \mathrm{g} / \mathrm{ml}$ ) was as follow; 90\% DM (12.45) >n-butanol (15.59) > ethyl acetate (21.36) >water (49.16) compared to ascorbic acid as standard with $\mathrm{SC}_{50}=7.50 \mu \mathrm{g} / \mathrm{ml}$ (Table 1). Moreover, except petroleum ether and DCM, all the tested fractions qualitatively showed white wider zones upon the dark purple 
background indicating their potential free radical scavenging activities compared with quercitin and ascorbic acid as standards (Fig. 1).

\section{GC-MS analysis of $90 \%$ defatted methanol extract}

Qualitative GC-MS analyses of the $90 \%$ DM of P. granatum peels (the highest antioxidant extract among all PE tested) identified thirty-six components (Table 2) representing 93.1\% of the tota extract composition. These compounds were identified qualitatively based on their retention times and mass spectral fragmentation patterns as;piperidin-4-ol, 1,3-dimethyl-2,4,6-triphenyl (19.87\%)

Table 1: Free radical scavenging antioxidant activities (DPPH) of the $90 \%$ DM extract of $P$. granatum peel and its derived sub-fractions

\begin{tabular}{ll}
\hline Sample & DPPH $\left(\mathbf{S C}_{\mathbf{5 0}}\right)(\boldsymbol{\mu g} / \mathbf{m l})$ \\
\hline $90 \%$ DM & $12.45 \pm 0.18$ \\
Petroleum ether & Not detected \\
DCM & Not detected \\
Ethyl acetate & $21.36 \pm 0.06$ \\
$n$-butanol & $15.59 \pm 0.17$ \\
Distilled water & $49.16 \pm 0.08$ \\
Ascorbic acid & $7.50 \pm 0.32$ \\
\hline
\end{tabular}

Results are expressed as mean values \pm standard deviation $(\mathrm{n}=3)$. $\mathrm{SC}_{50}$ : Scavenging concentration at 50\%, DPPH: 2,2'-diphenyl-1-picrylhydrazyl, DM: Diabetes mellitus, DCM: Dichloromethane 6,11-dihydroxy-5,12 naphthacenequinone-1-carboxylic acid (7.80\%), anthraquinone, 1,1'-iminodi- (7.70\%), thiourea, 1,1-diethyl-3(2-mercapto-5-benzoxazolyl) (6.22\%), phloroglucinol (6.08\%), 1H-benzimidazole (3.92\%), coumarin-6-ol, 3,4-dihydro-4,4dimethyl-5,7-dinitro (3.25\%), pseudobaptigenin (3.18\%), and 24,25-dihydroxyvitamin D3 (3.10\%), as the major components and other constituents were detected as minors (Fig. 2)

Effect of PE on the innate immunity of B. alexandrina and their susceptibility to $S$. mansoni infection

The effect of PE on the susceptibility of B. alexandrina snails to infection with $S$. mansoni parasite was evaluated after exposure of snails to these extracts for 1 month before infection. Snails exposed to an equivalent concentration for maximum antioxidant activity (200 ppm) of PE showed an infection rates of $20 \%, 50 \%, 60 \%, 70 \%$ and $80 \%$, respectively, for $90 \%$ DM, $n$-butanol, ethyl acetate, water and DCM compared to $95 \%$ in control snails. Although all the extracts caused a significant decrease in the infection rate of snails $(p \leq 0.05)$, the lowest infection rate was recorded with $90 \%$ DM (Table 3). Histological and microscopic examinations of the hemolymph and hermaphrodite glands before and after exposure to PE showed a significant increase in the hemocytes numbers and marked changes in their morphology after exposure. The number of hemocytes in the hemolymph of B. alexandrina snails was counted following 1 month in 90\% DM-exposed snails, while amoebocytes were significantly increased in exposed snails (70\%) compared to control (20\%), the numbers of granulocytes, and

Table 2: Chemical constituents identified in the $90 \%$ DM of $P$. granatum peel using GC-MS

\begin{tabular}{|c|c|c|c|}
\hline Peak No. & $\mathbf{R}_{\mathbf{t}}$ & Area \% & Identified compounds \\
\hline 1 & 3.11 & 4.35 & Unknown \\
\hline 2 & 4.9 & 1.52 & Unknown \\
\hline 3 & 10.09 & 6.08 & Phloroglucinol \\
\hline 4 & 10.64 & 1.09 & Anthraquinone, 1-(methylamino)-4-p-toluidino \\
\hline 5 & 11.48 & 0.41 & Zapotin \\
\hline 6 & 11.93 & 0.54 & Syringic acid \\
\hline 7 & 12.75 & 2.45 & 2-Iodohiistidine 2-([Bis (2 amino ethyl) amino] methyl) phenol \\
\hline \multirow[t]{2}{*}{9} & 13.7 & 0.67 & Cinnamic acid, 3,5-dimethoxy \\
\hline & & & Indole, 5-methyl-2-(4-pyridyl) \\
\hline 10 & 13.96 & 7.8 & 6,11-Dihydroxy-5,12 naphthacenequinone-1-carboxylic acid \\
\hline 11 & 14.19 & 1.43 & Caffeic acid dimethyl ether \\
\hline 12 & 14.44 & 6.22 & Thiourea, 1,1-diethyl-3-(2-mercapto-5-benzoxazolyl) \\
\hline 13 & 14.61 & 1.56 & Flavone, 3-hydroxy-4,,5,7-trimethoxy \\
\hline 14 & 14.69 & 1.82 & Papaveroline \\
\hline 15 & 14.77 & 1.2 & Bergenin \\
\hline 17 & 14.95 & 3.25 & Coumarin-6-ol, 3,4-dihydro-4,4-dimethyl-5,7-dinitro \\
\hline 18 & 15.18 & 0.56 & p-Menth-1-en-3-one, semicarbazone \\
\hline 19 & 15.33 & 1.0 & Piperazine, 1-(4-methoxyphenyl) \\
\hline 20 & 15.66 & 0.75 & Pyridine-3-carboxamide, 1,2-dihydro-4,6-dimethyl-2-thioxo \\
\hline 21 & 15.89 & 0.71 & Isoelemicin \\
\hline 22 & 16.18 & 1 & 5-Acetyl-2-methylpyridine thiosemicarbazone \\
\hline 23 & 16.44 & 0.82 & $\beta$-Asarone \\
\hline 24 & 16.71 & 0.68 & 4-[Ethylethanolamino]-1,2-naphthoquinone \\
\hline 25 & 16.92 & 19.87 & Piperidin-4-ol, 1,3-dimethyl-2,4,6-triphenyl \\
\hline 26 & 17.14 & 1.01 & $\beta$ carotene \\
\hline 27 & 17.24 & 3.92 & 1H-Benzimidazole \\
\hline 28 & 17.4 & 0.92 & Quinazolin-4 (3H)-one, 2-mercapto-3-(2-phenylethyl) \\
\hline 29 & 17.56 & 2.21 & p-Aminobenzoic acid \\
\hline 30 & 17.63 & 1.78 & Ethanone, 1-(6-methyl-3-pyridinyl) \\
\hline 31 & 18.03 & 3.1 & 24,25-Dihydroxyvitamin D3 \\
\hline 32 & 18.37 & 2.2 & Phenol, 4-amino-3,5-diethyl \\
\hline 33 & 18.61 & 7.70 & Anthraquinone, $1,1^{\prime}$-iminodi \\
\hline 36 & 19.28 & 0.51 & Piperazine, 1-(2-methoxyphenyl) \\
\hline 37 & 20.13 & 3.18 & Pseudobaptigenin \\
\hline 38 & 21.52 & 1.19 & Phenol, 4-nitro-2-(6,7-dimethylbenzo[e] dithiepan-2-yl) \\
\hline Total \% & & 93.1 & \\
\hline
\end{tabular}

DM: Defatted methanol, GC-MS: Gas chromatography-mass spectrometry 
Table 3: Infection rates of B. alexandrina snails exposed to PE for 1 month before infection with $S$. mansoni

\begin{tabular}{lllllll}
\hline Sample/control & $\mathbf{9 0 \%}$ DM & $\boldsymbol{n}$-butanol (\%) & Ethyl acetate (\%) & Water (\%) & DCM (\%) & Control (\%) \\
\hline Infection rate & $20^{*}$ & $50^{*}$ & $60^{*}$ & $70^{*}$ & $80^{*}$ & 95 \\
\hline *Highly significant at $\mathrm{p} \leq 0.05$ compared to control. DM: Diabetes mellitus, DCM: Dichloromethane & & &
\end{tabular}

hyalinocytes were significantly decreased. Their percentages were $50 \%$ and $30 \%$ compared to $20 \%$ and $5 \%$ in control, respectively, as shown in Table 4. There was also an increase in the hemocytes size in $90 \%$ DM-exposed snails due to an increase in their internal vacuoles (Fig. 3). With regard to the effect of $90 \%$ DM extract on the hermaphrodite glands of exposed snails, the glands showed clear maturation and expelling of mature gametes. Moreover, intensive condensations of spermatids and intense of the female acini with ova and oocytes were also observed including clear developmental stages $1^{\text {st }}$ and $2^{\text {nd }}$ oogonia (Fig. 4).

\section{DISCUSSION}

In this study, the different extracts of $P$ granatum L. peels were evaluated for their free radical scavenging antioxidant activity using DPPH assay in order to test it as immunostimulant against $S$. manson infection in intermediate host snails, $B$. alexandrina. It is apparent from Table 1 and Fig. 1 that 90\% DM and $n$-butanol are the most potent antioxidants. In the same context, the results of the DPPH antioxidant activity of $P$. granatum growing in India showed that the methanol extract exhibited highest activity followed by ethanol, acetone, and ethyl acetate extracts, moreover petroleum ether and benzene extracts showed a very weak activity [13]. Numerous studies have demonstrated that the high antioxidant activity of $P$. granatum may be due to the presence of a complex pattern of the bioactive polyphenolic compounds, i.e., phenolic acids, flavonoids, tannins, anthocyanins, quinones, and coumarins [13,46-48].

GC-MS analyses of the $90 \%$ DM of $P$ granatum peels identified 36 components representing $93.1 \%$ of the total extract composition. Based on their retention times and mass spectral fragmentation patterns, as the most prominent components were piperidin-4-ol, 1,3-dimethyl2,4,6-triphenyl, 6,11-dihydroxy-5,12 naphthacenequinone-1carboxylic acid, anthraquinone, 1,1'-iminodi, thiourea, 1,1-diethyl3-(2-mercapto-5-benzoxazolyl), and phloroglucinol. Kumar and Vijayalakshmi [49] identified 26 constituents from ethanolic extract of P. granatum peels, of which glycerin (27.03\%), hydroxymethylfurfurole (21.18\%), guanosine $(13.34 \%)$, and pyrogallol $(6.45 \%)$ were the major constituents. Moreover, GC-MS analysis of ethanolic extract of $P$. granatum revealed that it contains nitroisobutylglycerol $(19.02 \%)$, ethyl- $\alpha$-D-glucopyranoside $\quad(12.65 \%), \quad 3,5$-dihydroxy-6-methyl-2,3dihydro-4H-pyran-4-one (11.83\%), maltol (9.46\%), and 3H-indole3 -carbaldehyde (4-amino-5-methyl-4H-1,2,4 triazol-3-yl) hydrazone $(5.22 \%)$ as major constituents [50].

Following the evaluation the antioxidant activities of PE extracts and identification of its major constituents, their effects on B. alexandrina susceptibility to $S$. mansoni and changes in their hemocytes were investigated. The immune system of Biomphalaria is composed of cellular and humoral components acting independently or together to fight invading microbes or parasites $[51,52]$. The first line of defense is mediated by circulating phagocytic cells known as hemocytes (also known as amoebocytes) found in the hemolymph of the snail. These cells have an important role in phagocytosis and encapsulation reactions. During their course of development within snails, schistosomes larvae are in direct and intimate contact with the snail's tissues starts from miracidial penetration and ends with cercarial release within weeks after initial infection [53,54]. Many cellular and humoral factors have been studied with the hope that they might be used as indicators for measures of the effectiveness of potential immunostimulants [55]. Immunostimulants from medicinal plants can increase the resistance to disease by enhancing nonspecific and specific defense mechanisms [56-58]. The active compounds of
Table 4: Percentage of hemocytes in the hemolymph of B. alexandrina snails exposed to $90 \%$ DM extract for 1-month infection with $S$. mansoni

\begin{tabular}{llll}
\hline Sample type & $\begin{array}{l}\text { Granulocyte } \\
\text { (\%) }\end{array}$ & $\begin{array}{l}\text { Amoebocyte } \\
\text { (\%) }\end{array}$ & $\begin{array}{l}\text { Hyalinocyte } \\
\text { (\%) }\end{array}$ \\
\hline Control & 50 & 20 & 30 \\
$90 \%$ DM & $20^{*}$ & $70^{*}$ & $5^{*}$ \\
\hline
\end{tabular}

*Highly significant at $\mathrm{p} \leq 0.05$ compared to control. B. alexandrina: Biomphalaria alexandrina, S. mansoni: Schistosoma mansoni, DM: Diabetes mellitus

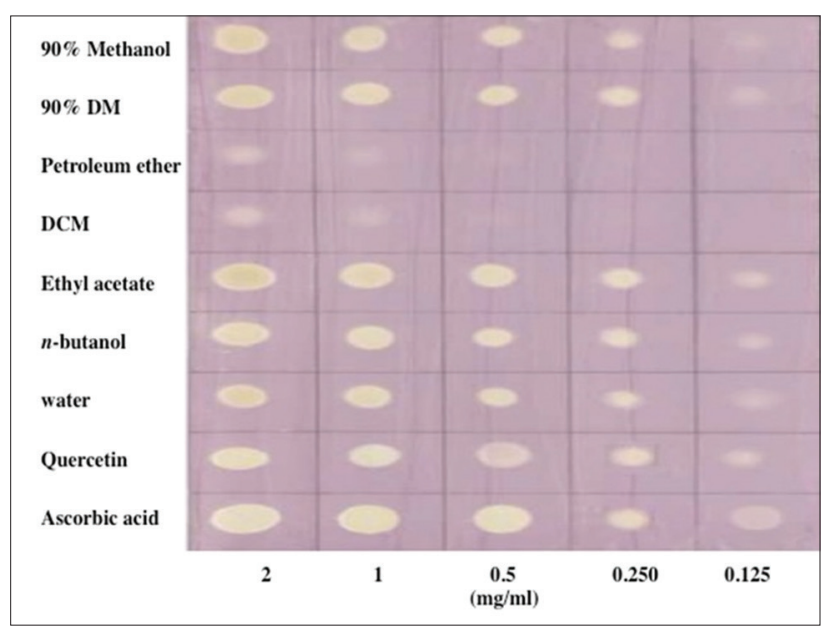

Fig. 1: Dot-blot qualitative antioxidant assay of different fractions of Punica granatum peels on silica sheet stained with 2,2'-diphenyl-1-picrylhydrazyl solution in methanol compared to quercetin and ascorbic acid as standards

plants activate several components of the immune system, such as phagocytes [59].

This study showed that all the extracts of P.granatum caused a significant decrease in the infection rate of snails $(p \leq 0.05)$. However, the lowest infection rate was recorded with $90 \%$ DM extract which reduced the infection rate to $20 \%$. This improvement in the resistance to infection in $90 \%$ DM-exposed snails could be attributed to its modulation to the hemocytes number and morphology of infected snails. A significant increase in the hemocytes numbers $(p \leq 0.05)$ and marked changes in their morphology were reported following exposure to $90 \% \mathrm{DM}$ extract. This increase in the hemocytes (amoebocytes) is of specific importance to snails since it represents the first line of defense and it is in direct contact with schistosomes larvae. The immune response of these blood cells is mediated by infiltration around the parasite, encapsulation, and phagocytosis. In a similar study, the phagocytosis activity of the fish Paralichthys olivaceus infected with lymphocystis disease virus significantly increased after the administration of aqueous, ethanol and methanol solvent extract of $P$. granatum at 50 and $100 \mathrm{mg} / \mathrm{kg}$ dose after 8 weeks. All the solvent extracts at 50 and $100 \mathrm{mg} / \mathrm{kg}$ doses increased the survival rate of infected fish [60]. The $90 \%$ DM extract has had an improving effect on the hermaphrodite glands of $B$. alexandrina as shown by intensive condensations of spermatids and female acini with ova and oocytes. In particular, this organ in the snails is sensitive for any change in optimum conditions. The beneficial effects of Punica $90 \%$ DM extract can be attributed to the antioxidant properties of the extract. 


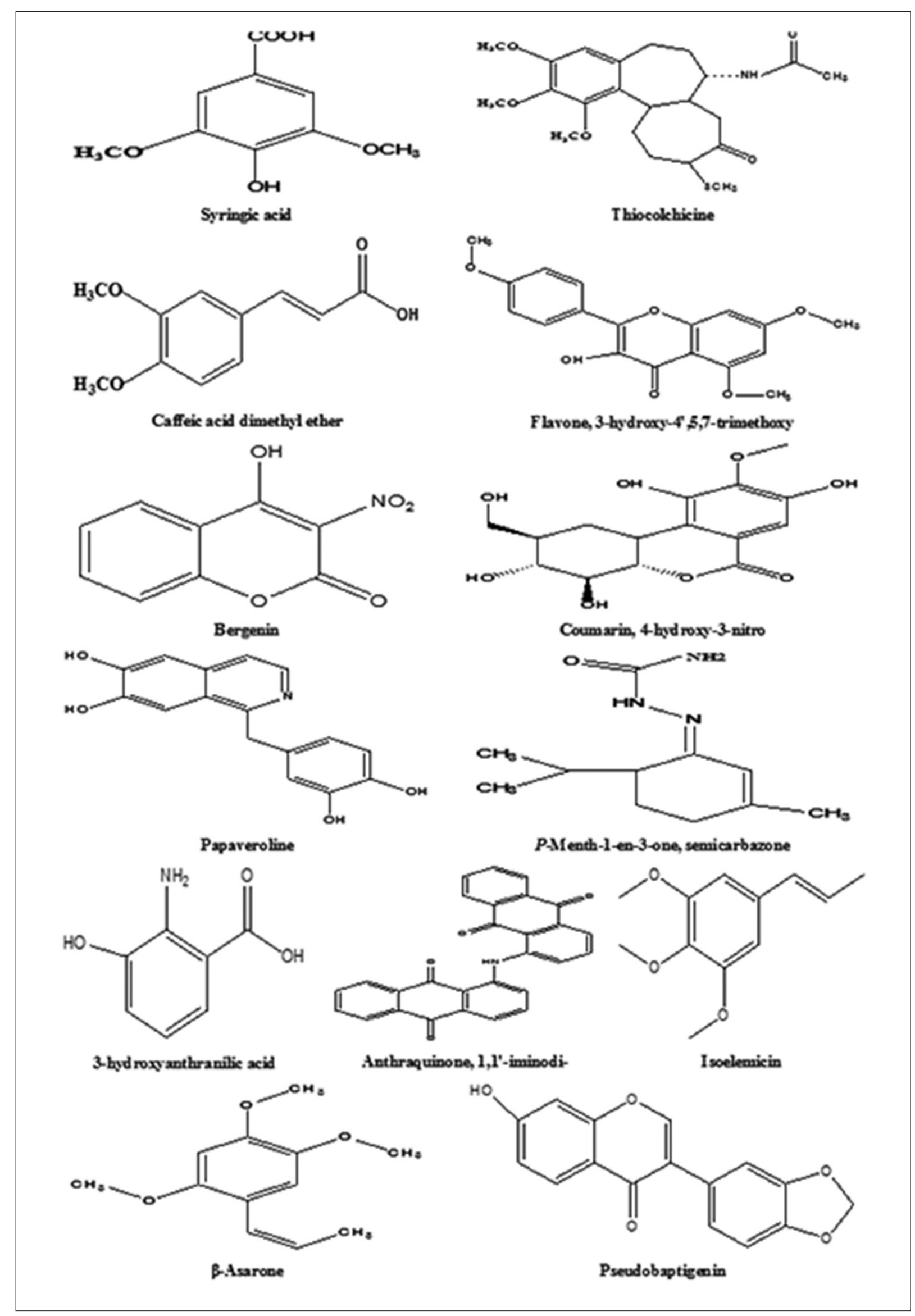

Fig. 2: Chemical structures of some identified compounds in the $\mathbf{9 0 \%}$ diabetes mellitus of Punica granatum peels by gas chromatographymass spectrometry analysis 


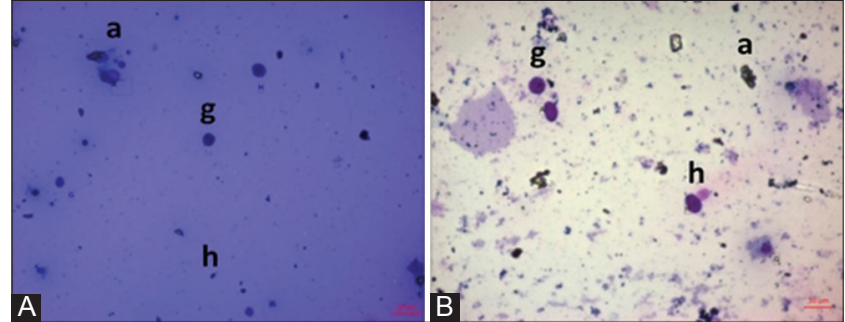

Fig. 3: Morphology of hemocytes in the hemolymph of Biomphalaria alexandrina in control and $90 \%$ diabetes mellitusexposed snails. (A) Control snails showing normal shape of the three hemocytes types (a) amoebocyte, (h) hyalinocyte and (g) granulocyte. (B) Exposed snails showing size increase in the three types of hemocytes, magnification at $\times 400$
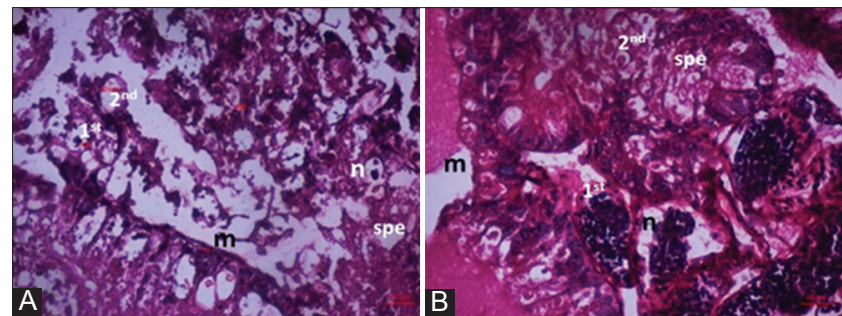

Fig. 4: Morphology of reproductive cells in the hermaphrodite glands of Biomphalaria alexandrina from control $90 \%$ diabetes mellitus-exposed snails. (A) Control snails (B) exposed snails showing healthy and clear developmental stages; (n) nucleus, (m) membrane, (spe) spermatogonia and $1^{\text {st }}$ and $2^{\text {nd }}$ oogonia, magnification at $\times 400$

Other medicinal plants were used as adaptogens and showed a similar immunostimulatory and protective effect. Boon-Niermeijer et al. studied the protective role of the phytoadaptogens herbs Acanthopanax senticosus and Rhodiola rosea against high and toxic dose of different environmental stressors using the embryos of the pond snail Lymnaea stagnalis as a model. The application of aqueous or ethanolic extracts of Acanthopanax (0.68 mg/ml) or Rhodiola ( $40.5 \mu \mathrm{g} / \mathrm{ml}$ ) for $20 \mathrm{hrs}$ to 3-day old embryos significantly protected against the negative effect of superoxide radicals induced by heavy metals and heat shock indicating the ability of these plant extract to enhance the resistance of Lymnaea offspring to the various stress conditions tested. The protective potential of phytoadaptogens may be attributed to their antioxidative properties [61].

\section{CONCLUSION}

In conclusion, this study showed that most of $P$. granatum extracts significantly improved the innate immunity of B. alexandrina and increased their resistance to $S$. mansoni infection at $200 \mathrm{ppm}$ concentration. This improvement in snails' resistance was positively correlated to the antioxidant activity of the tested extract. For example, $90 \%$ DM extract showed the highest antioxidant activity $\left(\mathrm{SC}_{50}=12.45\right)$ and reduced the snail's infection with $S$. mansoni to $20 \%$ compared to $95 \%$ in control. The extract can, therefore, be used as immunostimulant to hinder S. mansoni development within snails leading to inhibition of the parasite's life cycle and transmission. It also has an improving role on the reproductive organs of the snails as revealed by hermaphrodite glands histology. Finally, this activity may attribute to the chemical constituents that were identified via GC-MS analysis in 90\% DM extract.

\section{ACKNOWLEDGMENT}

This research is supported by an internal project $(100 \mathrm{M})$ from Theodor Bilharz Research Institute entitled "The role of some plants in raising resistance of snails to infection with trematodes."

\section{REFERENCES}

1. Harvey AL, Edrada-Ebel R, Quinn RJ. The re-emergence of natura products for drug discovery in the genomics era. Nat Rev Drug Discov 2015;14(2):111-29.

2. David B, Wolfender JL, Dias DA. The pharmaceutical industry and natural products: Historical status and new trends. Phytochem Rev 2015;14(2):299-315.

3. Bhat AH, Dar KB, Anees S, Zargar MA, Masood A, Sofi MA, et al. Oxidative stress, mitochondrial dysfunction and neurodegenerative diseases; A mechanistic insight. Biomed Pharmacother 2015;74:101-10.

4. Halliwell B, Gutteridge JM. Free Radicals in Biology and Medicine. USA: Oxford University Press; 2015.

5. Rajendran $P$, Nandakumar $N$, Rengarajan $T$, Palaniswami R, Gnanadhas EN, Lakshminarasaiah U, et al. Antioxidants and human diseases. Clin Chim Acta 2014;436:332-47.

6. Gyawali R, Ibrahim SA. Natural products as antimicrobial agents. Food Control 2014;46:412-29.

7. Harikrishnan R, Balasundaram C, Heo MS. Impact of plant products on innate and adaptive immune system of cultured finfish and shellfish. Aquaculture 2011;317(1-4):1-15.

8. Langeveld WT, Veldhuizen EJ, Burt SA. Synergy between essential oil components and antibiotics: A review. Crit Rev Microbiol 2014;40(1):76-94

9. Agarwal SS, Singh VK. Inmmunomodulators: A review of studies on Indian medicinal plants and synthetic peptides. Proc Indian Natl Sci Acad 1999;65:179-204.

10. Devasagayam TP, Sainis KB. Immune system and antioxidants, especially those derived from Indian medicinal plants. Indian J Exp Biol 2002;40(6):639-55.

11. Citarasu T. Herbal biomedicines: A new opportunity for aquaculture industry. Aquac Int 2010;18(3):403-14.

12. Voravuthikunchai S, Lortheeranuwat A, Jeeju W, Sririrak T, Phongpaichit S, Supawita T. Effective medicinal plants against enterohaemorrhagic Escherichia coli O157:H7. J Ethnopharmacol 2004;94(1):49-54.

13. Zahin M, Aqil F, Ahmad I. Broad spectrum antimutagenic activity of antioxidant active fraction of Punica granatum L. Peel extracts. Mutat Res 2010;703(2):99-107.

14. Chidambara Murthy KN, Jayaprakasha GK, Singh RP. Studies on antioxidant activity of pomegranate (Punica granatum) peel extract using in vivo models. J Agric Food Chem 2002;50(17):4791-5.

15. Çam M, İçyer NC, Erdoğan F. Pomegranate peel phenolics: Microencapsulation, storage stability and potential ingredient for functional food development. LWT-Food Sci Technol 2014;55(1):117-23

16. Singh RP, Chidambara Murthy KN, Jayaprakasha GK. Studies on the antioxidant activity of pomegranate (Punica granatum) peel and seed extracts using in vitro models. J Agric Food Chem 2002;50(1):81-6.

17. Heber D, Seeram NP, Wyatt H, Henning SM, Zhang Y, Ogden LG, et al. Safety and antioxidant activity of a pomegranate ellagitanninenriched polyphenol dietary supplement in overweight individuals with increased waist size. J Agric Food Chem 2007;55(24):10050-4.

18. Kumar VP, Chauhan NS, Padh H, Rajani M. Search for antibacterial and antifungal agents from selected Indian medicinal plants. J Ethnopharmacol 2006;107(2):182-8.

19. Costantini S, Rusolo F, De Vito V, Moccia S, Picariello G, Capone F, et al. Potential anti-inflammatory effects of the hydrophilic fraction of pomegranate (Punica granatum L.) Seed oil on breast cancer cell lines. Molecules 2014;19(6):8644-60.

20. Zarfeshany A, Asgary S, Javanmard SH. Potent health effects of pomegranate. Adv Biomed Res 2014;3(1):100.

21. Viladomiu M, Hontecillas R, Lu P, Bassaganya-Riera J. Preventive and prophylactic mechanisms of action of pomegranate bioactive constituents. Evid Based Complement Alternat Med 2013;2013:789764.

22. Wobeser GA. Essentials of Disease in Wild Animals. New York: John Wiley \& Sons; 2013.

23. Bockarie MJ, Kelly-Hope LA, Rebollo M, Molyneux DH. Preventive chemotherapy as a strategy for elimination of neglected tropical parasitic diseases: Endgame challenges. Philos Trans R Soc Lond B Biol Sci 2013;368(1623):20120144.

24. Steinmann P, Keiser J, Bos R, Tanner M, Utzinger J. Schistosomiasis and water resources development: Systematic review, meta-analysis, and estimates of people at risk. Lancet Infect Dis 2006;6(7):411-25.

25. Fenwick A, Savioli L, Engels D, Robert Bergquist N, Todd MH. Drugs for the control of parasitic diseases: Current status and development in 
schistosomiasis. Trends Parasitol 2003;19(11):509-15.

26. King $\mathrm{CH}$, Bertsch D. Historical perspective: Snail control to prevent schistosomiasis. PLoS Negl Trop Dis 2015;9(4):e0003657.

27. WHO. The Control of Schistosomiasis. Report of a WHO Expert Committee. Technical Report Series No 728. Geneva: WHO; 1985.

28. WHO. The Control of Schistosomiasis. Second Report of the WHO Expert Committee. Technical Report Series No 830. Geneva: WHO; 1993.

29. Fallon PG, Doenhoff MJ. Drug-resistant schistosomiasis: Resistance to praziquantel and oxamniquine induced in Schistosoma mansoni in mice is drug specific. Am J Trop Med Hyg 1994;51(1):83-8.

30. WHO. Schistosomiasis: Number of People Treated Worldwide in 2009. Weekly Epidemiological Record. Vol. 86. Geneva: WHO; 2011. p. $73-80$.

31. Abou-El-Naga IF. Meta-analysis indicates lack of local adaptation of Schistosoma mansoni to Biomphalaria alexandrina in Egypt. Parasitol Res 2014;113:1185-94

32. Elmorshedy H, Bergquist R, El-Ela NE, Eassa SM, Elsakka EE, Barakat R. Can human schistosomiasis mansoni control be sustained in high-risk transmission foci in Egypt? Parasit Vectors 2015;8:372.

33. Elsherif Y, Tharwa ES, Badra G, Salama M, Sharaf S, Waked I. Longterm effect of mass chemotherapy of Schistosoma mansoni on infection rate and diagnosis accuracy. Int $J$ Infect Dis 2015;41:79-82.

34. Mohamed AH, El-Din AT, Mohamed AM, Habib MR. The relationship between genetic variability and the susceptibility of Biomphalaria alexandrina snails to Schistosoma mansoni infection. Mem Inst Oswaldo Cruz 2012;107(3):326-37.

35. Mossalem HS, Abdel-Hamid H, El-Shinnawy NA. Impact of artemether on some histological and histochemical parameters in Biomphalaria alexandrina. Afr J Pharm Pharmacol 2013;7(31):2220-30.

36. Tennessen JA, Théron A, Marine M, Yeh JY, Rognon A, Blouin MS Hyperdiverse gene cluster in snail host conveys resistance to human schistosome parasites. PLoS Genet 2015;11(3): e1005067.

37. Molyneux P. The use of the stable free radical diphenylpicryl - Hydrazyl (DPPH) for estimating antioxidant activity. Songklanakarin J Sci Technol 2004;26(2):211-9.

38. Ghareeb MA, Hussein A, Hassan M, Laila A, Mona AM, Amal MS. Radical scavenging potential and cytotoxic activity of phenolic compounds from Tectona grandis Linn. Glob J Pharmacol 2013;7(4):486-97.

39. Shoeb HA, Madkour HM, Refahy LA, Mohamed MA, Saad AM, Ghareeb MA. Antioxidant and cytotoxic activities of Gmelina arborea ROXB. Leaves. Br J Pharm Res 2014;4(1):125.

40. Adams RP. Identification of Essential Oils by Ion Trap Mass Spectroscopy. New York: Academic Press; 2012.

41. Chernin E. Interference with the capacity of Schistosoma mansoni miracidia to infect the molluscan host. J Parasitol 1968;54(3):509-16.

42. Yousif F, Ibrahim A, el Bardicy SN. Compatibility of Biomphalaria alexandrina, Biomphalaria glabrata and a hybrid of both to seven strains of Schistosoma mansoni from Egypt. J Egypt Soc Parasitol 1998;28(3):863-81.

43. Michelson EH. Specificity of hemolymph antigens in taxonomic discrimination of medically important snails. J Parasitol 1966;52(3):466-72.

44. Mohamed AH, Sharaf El-Din AT, Mohamed AM, Habib MR. Tissue responses exhibited by Biomphalaria alexandrina snails from different Egyptian localities following Schistosoma mansoni exposure. Exp Parasitol 2011;127(4):789-94.

45. Annegowda HV, Nee CW, Mordi MN, Ramanathan S, Mansor SM.
Evaluation of phenolic content and antioxidant property of hydrolysed extracts of Terminalia catappa (L.) Leaf. Asian J Plant Sci 2010;9(8):479-85.

46. El-Sayed MM, Mahmoud M, El-Nahas H, El-Toumy S, El-Wakil EA Ghareeb M. Bio-guided isolation and structure elucidation of antioxidan compounds from the leaves of Ficus sycomorus. Pharmacolonline 2010;3:317-32

47. Ghareeb MA, Hussein A, Hassan M, Laila AR, Mona A, Amal M Antioxidant and cytotoxic activities of flavonoidal compounds from Gmelina arborea (Roxb.). Glob J Pharmacol 2014;8(1):87-97.

48. Zaki SA, Abdelatif SH, Abdelmohsen NR, Ismail FA. Phenolic compounds and antioxidant activities of pomeagranate peels. Int J Food Eng 2015;1(2):73-6.

49. Kumar A, Vijayalakshmi K. GC-MS analysis of phytochemica constituents in ethanolic extract of Punica granatum peel and Vitis vinifera seeds. Int J Pharm Bio Sci 2011;2(4):461-8.

50. Bonzanini F, Bruni R, Palla G, Serlataite N, Caligiani A. Identification and distribution of lignans in Punica granatum L. Fruit endocarp, pulp seeds, wood knots and commercial juices by GC-MS. Food Chem 2009;117:745-9.

51. Bayne CJ. Successful parasitism of vector snail Biomphalaria glabrata by the human blood fluke (trematode) Schistosoma mansoni: A 2009 assessment. Mol Biochem Parasitol 2009;165(1):8-18.

52. Coustau C, Gourbal B, Duval D, Yoshino TP, Adema CM, Mitta G Advances in gastropod immunity from the study of the interaction between the snail Biomphalaria glabrata and its parasites: A review of research progress over the last decade. Fish Shellfish Immuno 2015;46(1):5-16.

53. Loker ES, Adema CM, Zhang SM, Kepler TB. Invertebrate immune systems - not homogeneous, not simple, not well understood. Immunol Rev 2004;198:10-24.

54. Yoshino TP, Coustau C. Immunobiology of Biomphalaria-trematode interactions. In: Biomphalaria Snails and Larval Trematodes. New York: Springer; 2011. p. 159-89.

55. Sritunyalucksana K, Sithisarn P, Withayachumnarnkul B, Flegel TW Activation of prophenoloxidase, agglutinin and antibacterial activity in haemolymph of the black tiger prawn, Penaeus monodon, by immunostimulants. Fish Shellfish Immunol 1999;9(1):21-30.

56. Reverter M, Bontemps N, Lecchini D, Banaigs B, Sasal P. Use of plant extracts in fish aquaculture as an alternative to chemotherapy: Current status and future perspectives. Aquaculture 2014;433:50-61.

57. Puri A, Sahai R, Singh KL, Saxena R, Tandon J, Saxena K Immunostimulant activity of dry fruits and plant materials used in Indian traditional medical system for mothers after child birth and invalids. J Ethnopharmacol 2000;71(1):89-92.

58. Rowley AF, Powell A. Invertebrate immune systems specific, quasispecific, or nonspecific? J Immunol 2007;179(11):7209-14.

59. Wagner H, Proksch A, Riess-Maurer I, Vollmar A, Odenthal S, Stuppner $\mathrm{H}$, et al. Immunostimulating polysaccharides (heteroglycans) of higher plants. Preliminary communication. Arzneimittelforschung 1984;34(6):659-61.

60. Harikrishnan R, Heo J, Balasundaram C, Kim MC, Kim JS, Han YJ, et al. Effect of Punica granatum solvent extracts on immune system and disease resistance in Paralichthys olivaceus against lymphocystis disease virus (LDV). Fish Shellfish Immunol 2010;29(4):668-73.

61. Boon-Niermeijer EK, van den Berg A, Wikman G, Wiegant FA. Phytoadaptogens protect against environmental stress-induced death of embryos from the freshwater snail Lymnaea stagnalis. Phytomedicine 2000;7(5):389-99. 